\title{
ANALISIS SISTEM INFORMASI AKUNTANSI DALAM PEMBERIAN KREDIT PADA KOPPELOG BULOG MANADO
}

\author{
Jessica Brenda Suwatalbessy ${ }^{1}$, Jenny Morasa $^{2}$, Steven Tangkuman ${ }^{3}$ \\ 1,2,3 Jurusan Akuntansi, Fakultas Ekonomi dan Bisnis, Universitas Sam Ratulangi, Jl. Kampus Bahu, Manado, \\ 95115, Indonesia
}

E-mail : Jessicabrenda_S@yahoo.com

\begin{abstract}
Accounting information systems are the main formal system in most companies. Accounting information systems have an important role in lending in which companies can see the effectiveness of accounting systems in lending. The aim of the study was to find out how the procedure for granting credit at the Koppelog Bulog Manado. The results showed that the accounting information systems in giving credit to the Koppelog Bulog Manado was quite effective, but it was just that the lack of good quality resources in Koppelog Bulog Manado was due to the average level of education of employees who were not very skilled in their field.
\end{abstract}

Keywords : Accounting information systems, Procedure for granting, Credit

\section{PENDAHULUAN}

Semua aktivitas dan kegiatan ekonomi yang dilakukan bagi perusahaan akan diproses dalam suatu sistem yang disebut dengan SIA. SIA ini dibuat sedemikian rupa untuk suatu instansi sehingga dapat menjalankan perannya, adalah memberikan informasi akuntansi yang akurat, relevan, dan dapat diyakini. Dalam SIA mencangkup lima komponen didalamnya yaitu SDM, alat, catatan, formulir, dan prosedur. (Shiena, 2013). Perkembangan teknologi informasi sekarang ini menyebabkan lingkungan bisnis dipertemukan dengan kondisi dan situasi revalitas yang semakin mengetat yang menanti instansi akan melakukan bisnisnya semakin baik untuk mencapai sasaran perusahaan. Adanya SIA yang efesien akan menghasilkan informasi yang setakar dengan keperluan. Informasi yang efesien adalah informasi yang tercapai akurat, berfungsi dan dapat dipercaya. Salah satu strategis bagi setiap instansi adalah SIA (Adel, 2013).

Bagian terpenting yang dibutuhkan manajemen suatu perusahaan diantaranya adalah informasi akuntansi. Salah satu informasi akuntansi adalah yaitu data-data keuangan.Data keuangan yang memberikan manfaat bagi pihak manajemen perusahaan atau pihak ekstern atau para pengambil keputusan yang harus disajikan mengatur arus dan pengolahan data akuntansi yang biasa disebut dengan sistem informasi akuntansi. (Deser,2016). Setiap lembaga keuangan dituntut guna mengawasi pinjaman yang sudah diberikan supaya pelunasan dari kreditur terus berjalan mulus. Oleh sebab itu, lembaga keuangan harus mempunyai sistem informasi yang efesien agar pinjaman yang disalurkan bisa dilunasi sesuai dengan kebijakan. (Suartini, 2015). Tidak terkecuali dengan Koppelog yang juga merupakan lembaga keuangan non bank.

\section{TINJAUAN PUSTAKA}

Pengertian Akuntansi. Akuntansi merupakan suatu cara atau metode pendataan, pengelompokan, peringkasan, pengikhtisaran, penyajian pelaporan dari seluruh transaksi keuangan dalam setiap perusahaan. (krismiaji $2015: 15$ ).

Siklus Akuntansi. Pengertian siklus akuntansi adalah gambaran atau sebuah tahapan bagaimana aktivitas dalam setiap metode akuntansi dan laporan akuntansi, saat berjalannya 
suatu transaksi sampai dengan dilakukannya suatu laporan finansial. Menurut Dina Fitria (2014 : 28).

Pengertian Akuntansi Manajemen. Dalam mengelola usaha, baik usaha yang kecil maupun usaha yang besar ataupun melakukan usaha dagang, jasa dan manufaktur masing-masing membutuhkan yang namanya informasi akuntansi manajemen. Informasi ini dapat menjadi alat pengawasan dan dasar pengambilan keputusan bagi pihak internal perusahaan yaitu pihak manajemen. (Rudianto, $2013: 9$ ).

\section{Pengertian Sistem Informasi Akuntansi (SIA)}

Sistem Informasi. Mulyadi (2015 : 5), sistem adalah "suatu jaringan yang dibuat menurut pola yang terpadu untuk melaksanakan kegiatan pokok perusahaan”. Sedangkan menurut James Hall (2011 : 6), sistem adalah "sekelompok dua atau lebih komponen-komponen yang saling berkaitan (subsistem-subsistem yang bersatu untuk mencapai tujuan yang sama". Informasi adalah pemberitahuan atau kumpulan pesan (ekspresi atau ucapan) yang memberikan arti dan manfaat yang berguna untuk pengambilan keputusan yang tepat. (Al Bahra, 2013 ; 9).

Definisi Sistem Informasi Akuntansi. Moscove Zaki (2013 : 3) "Sistem Informasi Akuntansi adalah suatu komponen suatu organisasi yang mengumpulkan, menghasilkan, mengolah, menganalisa, mengkomunikasikan informasi finansial dan pengambilan keputusan yang relevan kepada pihak luar perusahaan maupun pihak intern".

Komponen Sistem Informasi Akuntansi. SIA mempunyai bagian komponen pokok, berdasarkan Krismiaji (2015 : 27) SIA adalah: (1) SDM; (2) Alat; (3) Metode; dan (4) Pelaporan.

Sasaran Sistem Informasi Akuntansi. Berdasarkan Azhar Susanto (2013: 8) sasaran atau maksud SIA adalah sebagai berikut:

"Bagi suatu perusahaan, sistem informasi akuntansi dibangun dengan tujuan utama untuk mengolah data keuangan yang berasal dari berbagai macam sumber menjadi informasi akuntansi yang diperlukan oleh berbagai macam penilaian. Pemakai informasi tersebut dapat berasal dari dalam perusahaan seperti manajer atau dari luar seperti pelanggan dan pemasok".

Manfaat Sistem Informasi Akuntansi (SIA). Manfaat SIA menurut Dina (2012 : 19) adalah : (1) menjaga kekayaan/aset instansi; (2) mengadakan beragam pesan; (3) mengadakan pesan bagi pihak luar instansi; (4) mengadakan pesan bagi pengiraan kinerja pegawai; (5) mempersiapkan dokumen masa lampau untuk kebutuhan audit; (6) menadakan pesan bagi asifikasi dan pertimbangan bujet perusahaan; dan (7) mengadakan pesan yang dibutuhkan dalam aktivitas perangkaan dan pengoperasian.

Koperasi Koppelog. Koperasi koppelog adalah singkatan dari koperasi pegawai logistik, yaitu koperasi ini berbentuk koperasi primer, yang bertujuan untuk mensejahterakan setiap anggotanya, memperoleh status Badan Hukum nomor 2011/BH/V tanggal 28 Juni 1982, berdiri dalam waktu yang tidak terbatas, berdasarkan Pancasila dan Undang-Undang Dasar 1945.

Pemberian Kredit. Maksud dari pemberian kredit adalah atas dasar kepercayaan akan kebenaran atas persetujuan dari kedua belah pihak antara pihak yang memberikan pinjaman yang mewajibkan peminjam untuk melunaskan utangnya setelah jangka waktu tertentu yang diberikan. (Krismiaji, $2015: 16$ ).

\section{METODE PENELITIAN}

Jenis Penelitian. Penelitian dilaksanakan dengan cara menggunakan penelitian kualitatif. Penelitian kualitatif yaitu penelitian ilmiah mengenai penyelidikan yang bertemperamen deskriptif dan lebih mengarah pada penjabaran atau penyelidikan. 
Tempat dan Waktu Penelitian. Penelitian ini dilakukan di Kantor Bulog Manado bertempat di Jl. Wr.Supratman, Mahakeret Barat Wenang Manado Sulawesi Utara. Penelitian dilakukan pada mulai bulan Januari 2018 hingga bulan Juni 2018.

Prosedur Penelitian. Prosedur penelitian ini dilakukan yaitu dengan langkah-langkah sebagai berikut: (1) permohonan ijin agar melakukan penelitian di kantor bulog manado; (2) pengamatan secara langsung; (3) mengolah data yang sudah ada; (4) mengkaji data; (5) menguraikan data; (6) menjabarkan data; dan (7) membuat kesimpulan dari hasil penelitian.

Sumber Data. Sumber data terbagi atas dua bagian yaitu :

1. Data primer adalah data yang menunjukan pada informasi yang didapat dari tangan pertama oleh penelitiyang berkaitan dengan variabel minat untuk tujuan spesifik studi.

2. Data Sekunder adalah data yang menunjukan pada informasi yang dikumpulkan dari sumber yang telah ada.

Metode Pengumpulan Data. Metode yang dipakai pada penelitian ini memakai metode yaitu :

1. Metode interviu. Merupakan metode yang dilakukan untuk mengajukan atau memberikan sebuah pertanyaan kepada pimpinan koperasi.

2. Metode observasi. Merupakan metode yang dilakukan untuk melihat situasi keadaan dan masalah yang dihadapi oleh koperasi.

3. Metode dokumentasi. Merupakan metode yang dilakukan dengan menghimpunkan data melalui dokumen dan berkas yaitu meliputi : (1) struktur organisasi; (2) alur proses pemberian kredit; (3) surat permohonan pemberian kredit; (4) surat persetujuan permohonan kredit; dan (5) perangkat analisa pemberian kredit..

Metode Analisis. Metode analisis data yang dipakai dalam penelitian ini adalah menggabungkan data, penyajian data, reduksi data, dan menarik kesimpulan untuk menjawab mengenai permasalahan yaitu bagaimana prosedur pemberian kredit pada koppelog bulog dan apakah implementasi SIA dalam pemberian kredit pada koppelog bulog sudah sesuai dengan SOP yaitu menggunakan teknik analisis deskrptif. 


\section{HASIL DAN PEMBAHASAN}

\subsection{Hasil Penelitian}

\section{Prosedur pemberian kredit di Koppelog Bulog Manado}

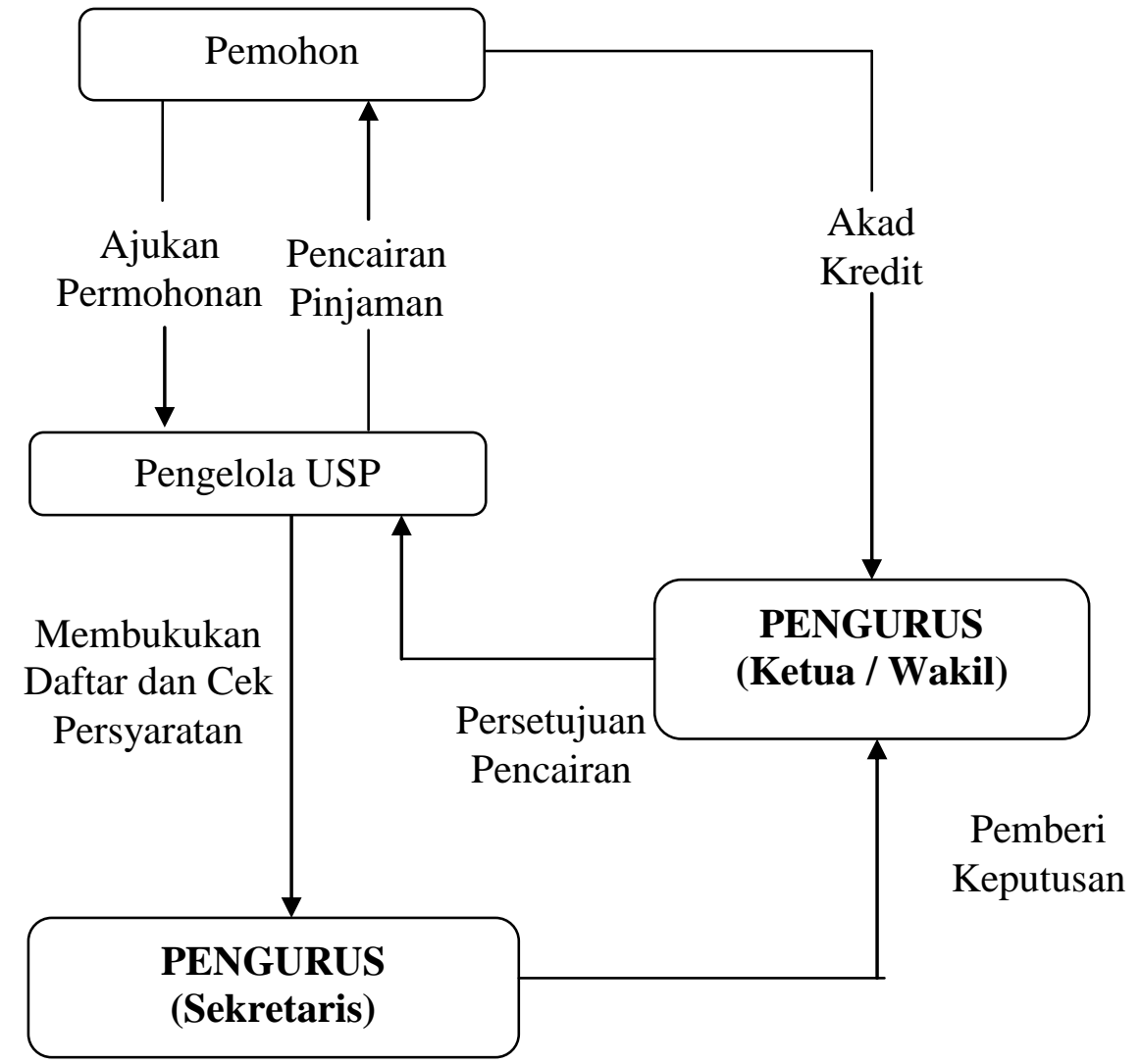

Final Check:

- Persyaratan

- Konfirmasi Kelayakan/Kredibilitas Pemohon

Sumber: Koppelog Bulog (2016)

\section{Analisis Terhadap Sistem Informasi Akuntansi Pemberian Kredit Pada Koppelog Bulog Manado}

1. Sumber Daya Manusia (SDM), strategi dan paraktik SDM (human resource policies and practices). Perusahaan memiliki Standard Opersional Prosedure (SOP), dan Buku Panduan Perusahaan (BPP) yang mesti dilakukan oleh karyawan. SOP tersebut berbeda untuk masing-masing bagian dikarenakan job description berbeda untuk masing-masing bagian. Dan dalam pemberian kredit, mulai dari tahap pemasukan berkas maka baik calon anggota maupun karyawan bagian kredit harus berlandaskan pada SOP yang telah ditetapkan oleh sebuah perusahaan. Hal tersebut sebagai upaya untuk menjaga kredit yang diberikan agar tidak macet atau tidak bermasalah. Setiap karyawan mempunyai kompetensi. Karyawan bagian kredit yang menjalankan fungsinya dengan baik, mulai dari fungsi penerimaan berkas calon anggota, proses pencairan kredit, dan pemantauan/pengawasan pembayaran angsuran kredit dilakukan dengan baik, sehingga munculnya kredit bermasalah itu sangat minim, juga ketika penyelesaian kredit diragukan dapat ditangani dengan baik sehingga kredit tersebut menjadi lancar kembali, maka pihak perusahaan akan memberikan sebuah apresiasi atau penghargaan berupa bonus ataupun kenaikan jabatan. Selain itu koperasi juga melakukan penilaian untuk mengetahui sejauh 
mana komitmen karyawan dalam menyelesaikan tugas yang telah diberikan. Pimpinan koperasi melakukan fungsi evaluasi kinerja karyawan dengan adanya meeting target. Sebelum melaksanakan kegiatan tiap dilaksanakan breafing yang dipimpin langsung oleh pimpinan koperasi dan hal-hal yang dibahas dalam breafing adalah target, tujuan, dan pencapaian selain itu arahan dalam pembagian tugas juga memberi pujian pada karyawan tertentu sesuai dengan prestasi yang mereka capai.

Tabel 1. Tingkat Pendidikan Pegawai Perum Bulog Manado

\begin{tabular}{clc}
\hline No. & \multicolumn{1}{c}{ Tingkat Pendidikan } & Jumlah \\
\hline 1. & Sarjana Strata 2 & 3 \\
2. & Sarjana Strata 1 & 19 \\
3. & Diploma 3 & 7 \\
4. & SLTA & 37 \\
5. & SLTP & 4 \\
6. & SD $\quad$ Total & 2 \\
& & 72 \\
\hline
\end{tabular}

Sumber: Koppelog Bulog

2. Alat, yang dipakai dalam SIA pemberian kredit pada koppelog adalah komputer. Komputer adalah suatu sistem yang terdiri dari serangkaian komponen Perangkat keras (hardware), meliputi yang bekerja secara elektronik dibawah pengendalian sistem operasi. Perangkat lunak (software), melaksanakan instruksi-instruksi, mempunyai kapasitas memori dan tempat penyimpanan (Internal Storage).

3. Catatan, catatan yang dipakai dalam SIA pemberian kredit pada Koppelog Bulog Manado yaitu. rekapitulasi Mutasi Harian Pinjaman (RKMHP), mutasi transaksi kas (MTK), jurnal, daftar nominatif pinjaman (DNP).

4. Formulir, pada koppelog bulog Manado mempunyai formulir-formulir yang dipakai dalam SIA pemberian kredit adalah sebagai berikut: SPK, PBK, BPgU, BSP, PJK dan KPJ.

5. Prosedur, merupakan langkah-langkah yang mesti dilalui sebelum suatu pinjaman itu dicairkan. Tujuannya adalah untuk mempermudah pihak yang memberikan kredit dalam penilaian kelayakan suatu permohonan kredit.

\subsection{Pembahasan}

\section{Sistem Informasi Akuntansi Pemberian Kredit Pada Koppelog Bulog Manado}

1. SDM. Melihat hasil penelitian yang ada menunjukan bahwa karyawan yang ada pada koperasi koppelog bulog Manado masih belum sebanding dengan kapasitas dan tugasnya kondisi ini dapat diamati dari tingkat edukasi rata-rata yang belum sesuai dengan keahliannya. Disebabkan sebagian besar adalah tamatan SLTA bukan sastrawan.

2. Alat. Melihat hasil menunjukan alat-alat yang dipakai dalam SIA pemberian kredit pada koppelog bulog Manado sudah terkomputerisasi yaitu dalam proses pemberian kredit mereka menggunakan alat komputer yang dilengkapi dengan aplikasi (MIS) Abacus, yang bisa dikatakan sudah cukup efesien dalam melakukan kegiatan pemberian kredit.

3. Catatan. Melihat hasil menunjukan catatan akuntansi yang dipakai dalam SIA pemberian kredit pada koppelog bulog Manado yaitu RKMHP, MTK, DNP, jurnal pengeluaran kas, buku besar, dan buku anggota. Catatan-catatan akuntansi yang dipakai sudah mencatat semua transaksi dalam periode akuntansi yang sebetulnya.

4. Formulir. Melihat hasil menunjukan, formulir yang dipakai dalam prosedur pemberian kredit pada koppelog terdiri atas SPK, PBK, BPgu. BSP, KPJ, dan PJK. Formulir yang dipakai dalam prosedur pemberian kredit sudah cukup baik. 
5. Prosedur. Melihat hasil menunjukan prosedur pemberian kredit pada koppelog bulog Manado dilakukan dengan langkah-langkah mulai dari tahap permohonan kredit, tahap penilaian kredit, tahap pemutusan kredit, tahap pengawasan kredit, dan tahap pencairan kredit. Tahap-tahap yang dipakai dalam proses pemberian kredit pada koppelog sudah sesuai dengan aturan standart operasional prosedur (SOP) dalam koperasi.

Tabel 2. Standar Operasional Prosedur

\begin{tabular}{|c|c|c|}
\hline $\begin{array}{c}\text { Prosedur Menurut Aturan } \\
\text { SOP }\end{array}$ & Pelaksanaan & Keterangan \\
\hline $\begin{array}{l}\text { - Permohonan Kredit } \\
\text { (kegiatan untuk mengajukan } \\
\text { permohonan kredit secara } \\
\text { tertulis dan mengumpulkan } \\
\text { berkas-berkas sebagai salah } \\
\text { satu syarat permohonan kredit). }\end{array}$ & $\begin{array}{l}\text { Kegiatan permohonan kredit } \\
\text { pada koppelog dilakukan } \\
\text { dengan memenuhi syarat-syarat } \\
\text { permohonan kredit yaitu : } \\
\text { - anggota koperasi } \\
\text { - surat permohonan } \\
\text { pinjaman } \\
\text { - tidak ada pinjaman di } \\
\text { koperasi } \\
\text { - menyerahkan identitas diri } \\
\text { berupa fotocopy KTP, Kartu } \\
\text { Keluarga, dan Surat Nikah. } \\
\text { - fotocopy rekening } \\
\text { tabungan } \\
\text { - slip gaji } \\
\text { - membuat permohonan } \\
\text { yang ditandatangani oleh } \\
\text { suami atau istri. }\end{array}$ & \\
\hline $\begin{array}{l}\text { - Penilaian Kredit } \\
\text { (kegiatan penilaian kredit } \\
\text { dengan mempersiapkan } \\
\text { penguraian dari segala aspek } \\
\text { kegiatan pemberian kredit) }\end{array}$ & $\begin{array}{l}\text { Kegiatan penilaian kredit pada } \\
\text { koppelog dilakukan dengan } \\
\text { mengevaluasi terhadap } \\
\text { kelayakan kredit untuk } \\
\text { mengetahui kemungkinan dapat } \\
\text { tidaknya dipertimbangkan } \\
\text { suatu permohonan kredit yang } \\
\text { didasarkan atas bahwa anggota } \\
\text { tidak memiliki pinjaman } \\
\text { sebelumnya. ya }\end{array}$ & Sesuai \\
\hline $\begin{array}{l}\text { - Pengawasan Kredit } \\
\text { (Pekerjaan yang meliputi } \\
\text { pengawasan aktif } \\
\text { pengawasan pasif) }\end{array}$ & $\begin{array}{l}\text { Kegiatan pengawasan kredit } \\
\text { pada koppelog dilakukan oleh } \\
\text { pihak koperasi baik secara } \\
\text { keseluruhan maupun secara } \\
\text { individual per anggota/ } \\
\text { peminjam yang bersifat } \\
\text { pengawasan aktif yaitu } \\
\text { pengawasan dilakukan dengan } \\
\text { on the spot, artinya menggali } \\
\text { informasi sebanyak-banyaknya } \\
\text { dari pihak anggota atau pihak }\end{array}$ & Sesuai \\
\hline
\end{tabular}


Tabel 2. Standar Operasional Prosedur

\begin{tabular}{cll}
\hline $\begin{array}{c}\text { Prosedur Menurut Aturan } \\
\text { SOP }\end{array}$ & \multicolumn{1}{c}{ Pelaksanaan } & Keterangan \\
\hline & $\begin{array}{l}\text { peminjam. Dan pengawasan } \\
\text { pasif dilakukan melalui } \\
\text { laporan-laporan tertulis. }\end{array}$ \\
& & Kegiatan pencairan kredit pada Sesuai \\
- Pencairan Kredit & koppelog dilakukan dengan \\
(Kegiatan pencairan & kredit \\
harus terjamin azaz aman, & $\begin{array}{l}\text { membenarkan bahwa seluruh } \\
\text { kegiatan yang terkandung } \\
\text { terarah, dan produktif. }\end{array}$ & $\begin{array}{l}\text { dalam persetujuan kredit telah } \\
\text { memenuhi atau dituntaskan dan } \\
\text { seluruh syarat yang ditetapkan } \\
\text { sudah lengkap sehingga } \\
\text { koperasi bisa mengadakan } \\
\text { proses pencairan. }\end{array}$ \\
&
\end{tabular}

\section{KESIMPULAN DAN SARAN}

\subsection{Kesimpulan}

Secara keseluruhan sistem informasi akuntansi dalam prosedur pemberian kredit di koppelog bulog Manado telah berjalan cukup efektif. Prosedur pemberian kredit pada koppelog telah mengikuti lima unsur-unsur SIA dan aturan yang dipakai dalam prosedur pemberian kredit sudah mengikuti standart operasional prosedur (SOP) pemberian kredit yang ditetapkan dan membantu proses pemberian kredit di koppelog bulog Manado.

\subsection{Saran}

1. Khusus untuk koppelog bulog Manado disarankan untuk menambah karyawan bagian analisis kredit yang berhubung dengan banyaknya anggota.

2.. Koppelog Bulog Manado agar dapat melakukan lebih perbaikan dan evaluasi mengenai sistem informasi akuntansi dalam prosedur pemberian kredit agar lebih efektif lagi.

3. Kepada atasan atau kepala koppelog bulog Manado, alangkah baiknya para pegawai dibekali pengetahuan tentang dasar-dasar sistem informasi akuntansi dalam prosedur pemberian kredit yang terdapat dikoppelog bulog Manado. Sehingga pegawai menjalankan tugasnya dengan baik sesuai dengan ahli bidangnya.

$\begin{array}{lcc} & \text { DAFTAR PUSTAKA } \\ \text { Anugerah Dino, } & 2016 . k o n s e p & \text { dasar }\end{array}$ http://www.anugerahdino.com/2015/02/konsep-dasar-akuntansi.html?m =1. Di akses : Januari, 26, 2018.

Anasthasia's Blog, 2017, Pengertian Struktur Organisasi. http://primanthaeveline.blogspot.co.id/2016/04/pengertian-struktur-organisasimenurut.html?m=1.di akses oktober, 09, 2017.

Atkinson, A, Antony., Kaplan, S, Robert., Matsumura, Mae, Ella, young, Mark S, 2013. Management Accounting. Edisi : 6. Pearson Education, inc. New Jersey.

Azhar Susanto. 2015. Sistem informasi akuntansi. Bandung. Lingga jaya.

Dessler, Gary. 2017. Manajemen Sumber Daya Manusia. Jakarta: Salemba Empat. Tanjungpinang. 
Dwiyatmanto, Husaini Ahmad. 2014. Analisis sistem pemberian kredit multiguna dalam upaya meningkatkan pengendalian kredit. (Studi pada Bank jatim Tbk cabang Lampung). JAB. Vol 22 No 2. Mei 2014. Universitas Brawijaya.

Ferry Rinaldi, 2013. Pengertian, fungsi, tujuan, dan ruang lingkup akuntansi manajemen. https://www.kembar.pro/2013/05/pengertian-fungsi-tujuan-akuntansimanajemen.html?m=1. Di akses : Januari, 302018.

Haidar server, 2016. Konsep dasar akuntansi (basic Accounting concept). https://haidarserver.blogspot.co.id/2016/02/konsep-dasar-akuntansi-basicaccounting.html?m=1. Di akses : Januari, 26, 2018.

Indrawan, Rully dan Yaniawati, Poppy. 2015. Metodologi Penelitian Kuantitatif dan Kualitatif, dan Campuran untuk Manajemen, Pembangunan dan Pendidikan. PT. Refika Aditama. Bandung

Lubis, Arfan Ikhsan. 2016. Akuntansi Keperilakuan. Edisi Dua. Jakarta: Salemba Empat.

Wilson, 2017. Pengertian manajemen perusahaan menurut para ahli lengkap. http://www.spengetahuan.com/2017/05/pengertian-manajemen-perusahaan-menurutpara-ahli-lengkap.html, di akses : Januari, 24, 2018

Yakub, 2014. Pengantar Sistem Informasi. Yogyakarta: Graha Ilmu. www.depkop.go.id di akses pada 20 Februari 2015 jam 19:30, dari http://www.depkop.go.id/index.php?option=com_phocadownload\&view= category\&id=128:data-koperasi-2014\&Itemid=93. 